\title{
KAJIAN FILOLOGI DAN NILAI PENDIDIKAN DALAM LONTAR TUTUR AJI SARASWATI
}

\author{
Oleh: \\ Gek Diah Desi Sentana, SS., M.Hum \\ gekdiahdesisentana@gmail.com \\ Institut Hindu Dharma Negeri Denpasar
}

\begin{abstract}
ABSTRAK
Kesusatraan sebagai suatu hasil karya pengarang atau pengawi berupa tulisan yang mengandung nilai-nilai budhi pekerti yang luhur serta memiliki nilai keindahan. Kesusastraan Bali dibagi menjadi dua, yaitu kesusastraan Bali Purwa dan kesusastraan Bali Anyar (modern). Kesusastraan Bali purwa yaitu kesusastraan yang tertua di Bali, yang sering disebut dengan kesusastraan rakyat yang menjadi sebuah tradisi turun-temurun hingga saat ini. Sedangkan kesusastraan Bali Anyar adalah hasil karya cipta seseorang yang menceritakan kehidupan masyarakat yang sudah dipengaruhi oleh dunia luar. Salah satu kesusastraan yang termasuk bagian dari kesusastraan Bali Purwa yaitu, kesusastraan berupa lontar sebagai warisan budaya, yang ditulis oleh para leluhur di atas daun lontar (daun ental). Dari keunikan masing-masing karya sastra tersebut, tertarik untuk mengkaji lontar TuturAji Saraswati yang akan dibahas pada tulisan ini mengenai perbandingan dan nilai pendidikan yang terkandung dalam lontar TuturAji Saraswati. Karena dalam lontar tersebut mengandung pengetahuan tentang aksara Bali. Lontar Tutur Aji Saraswati digunakan untuk mengetahui aksara bali yang terdapat dalam Bhuana Agung dan BhuanaAlit, begitu juga untuk mempermudah kita mempelajari sastra-sastra yang terdapat dalam Wariga, Usadha, Tutur, Agama dan intisari beserta penjelasannya.
\end{abstract}

\section{PENDAHULUAN}

Suatu karya sastra yang ditulis pada daun lontar hanya tersedia dalam sebuah atau sejumlah kecil naskah yang masing-masing ditandai dengan keunikan-keunikan tersendiri dan ditulis tangan yang khas. Hal terserbut membuat pembaca sering mengalami kesulitan untuk mengikuti alur cerita atau menangkap amanatnya, apalagi menikmati manfaat sastranya, relative lebih kecil. Begitu pula dengan keadaan media tulis yang berupa daun lontar, memungkinkan karya sastra tersebut bisa rusak atau sulit dibaca karena lontar yang digunakan kualitasnya kurang baik. Jika sebuah teks sudah ditranslitrasi atau disalin dari tulisan asli ke tulisan yang lebih kita kenal dan mengetiknya, maka kita akan lebih mudah memahami isi karya sastra tersebut. Namun, terkadang teks itu ditulis dalam bahasa atau idiom yang tidak kita kenal.

Kita sering beranggapan suatu karya sastra merupakan hasil pemikiran artinya, karya sastra yang diciptakan oleh seseorang digunakan sebagai wahana untuk mengungkapkan pikiran, gagasan, perasaan, dan kepercayaan. Dalam sebuah karya sastra akan menceritakan pikiran penulisnya dan masyarakatnya, yang menyangkut berbagai hal tentang apa yang diperhatikan serta apa yang dianggap penting, bagus dan berguna. Selain itu adanya pengaruh institusi sosial yang berubah dari waktu ke waktu dan etika kemarin tidak harus sama 
dengan etika hari ini. Dari keunikan masingmasing karya sastra tersebut, tertarik untuk mengkaji lontar Tutur Aji Saraswati yang akan dibahas pada tulisan ini mengenai perbandingan dan nilai pendidikan yang terkandung dalam lontar TuturAji Saraswati. Karena dalam lontar tersebut mengandung pengetahuan tentang aksara Bali. Lontar Tutur Aji Saraswati digunakan untuk mengetahui aksara bali yang terdapat dalam BhuanaAgung dan BhuanaAlit, begitu juga untuk mempermudah kita mempelajari sastra-sastra yang terdapat dalam Wariga, Usadha, Tutur, Agama dan intisari beserta penjelasannya. Berdasarkan latar belakang masalah di atas maka akan dibahas mengenai pada bagian mana struktur teks lontar tuturAji Saraswati yang disalin oleh pengarang yang berbeda dan nilai-nilai apakah yang terkandung dalam lontar tutur Aji Saraswati?

\section{PEMBAHASAN}

Kata perbandingan dalam bahasa Indonesia secara umum berarti suatu kegiatan untuk memperoleh hasil yang didapatkan dengan membandingkan dua atau lebih objek. Dalam hal ini perbandingan yang dimaksud adalah perbanndingan karya sastra yang berupa lontar. Perbandingan karya sastra menurut salah satu pakar mengatakan, Menurut Hosilos (2001 : 28) menyatakan bahwa perbandingan sebuah karya sastra mengacu pada dua hal. Pertama, sastra bandingan mengkaji perbandingan antara karya sastra pengarang satu dengan pengarang lain yang hidup didua Negara yang berbeda. Kedua, sastra bandingan mengkaji perbandingan antara karya sastra dengan karya seni yang lain, seperti seni lukis, seni music dan seni lainnya. Bahkan pada konsep kedua ini sastra dapat diperbandingkan dengan dua bidang ilmu dan kepercayaan lain atau diluar sastra. Untuk mendapatkan hasil perbandingan yang baik, dapat dilakukan dengan membaca karya sastra yang dibandingkan tersebut dengan saksama dan memahami isi secara mendalam. Membandingkan suatu karya sastra dengan karya sastra yang lain bertujuan untuk mendeskripsikan kemiripan dari dua objek yang berbeda pengarang dan latar budaya.

Pendidikan adalah suatu yang diyakini kebenarannya dan mendorong orang untuk berbuat positif didalam kehidupannya sendiri atau dimasyarakat. Sehingga nilai pendidikan dalam karya sastra dimaksud adalah nilai-nilai yang bertujuan untuk mendidik seseorang atau individu agar menjadi manusia yang baik dalam arti berpendidikan. Pendidikan berarti usaha membina kepribadiannya sesuai dengan nilainilai didalam masyarakat dan kebudayaan (Hasbullah, 2006: 1). Pendidikan adalah setiap usaha, pengaruh, perlindungan dan bantuan yang diberikan kepada anak tertuju atau yang lebih tepat membantu agar anak cakap melaksanakan tugas kehidupannya sendiri (Langeveld dalam Hasbullah, 2006 : 2) Menurut Kalpan dan Manners (2002: 15-16) teori memiliki fungsi ganda, disamping menjelaskan fakta yang sudah diketahui sebelumnya, yang lebih penting justru membuka wawasan baru yang dapat mengantarkan peneliti dan pembaca untuk menemukan fakta yang baru. Secara sederhana dapat dikatakan bahwa atas dasar fakta yang sudah ada dimungkinkan untuk menemukan fakta baru. Dikaitkan dengan penggunaan teori itu sendiri ada dua pendapat berbeda tentang teori. Dalam penelitian pertama peneliti menggunakan secara langsung teori-teori yang sudah ada, teori yang dianggap relevan, teori-teori yang ditemukan oleh orang lain. Teori ini sangat banyak, pada 
umumnya dibedakan menjadi dua yaitu teori positiveistik dan teori kritis. Teori kritis dibedakan menjadi dua yaitu teori kritis I dan teori kritis II. Teori kritis I dikenal dengan sebutan teori strukturalisme, keseluruhan teori dengan intensitas oposisi biner, seperti teori konflik, struktur fungsi, dramaturgi Goffman, pertukaran blau dan keseluruhan teori yang masih mempertahankan unsure sebagai gejala yang berdiri sendiri. Teori kritis II lebih dikenal dengan teori poststrukturalisme, teori-teori yang membalikkan oposisi biner, interdependensi penanda dan petanda, unsure-unsur dengan totalitas, seperti semiotika, interteks, resepsi, hegemoni, feminis, komodifikasi, interaksi simbolik, postkolonialisme, dekonstruksi dansebagainya.

Teori pada gilirannya berada pada posisi dilematis. Dalam penulisan sebuah karyailmiah teori harus ada sebelum analisis dilakukan, dalam hal ini peneliti jelas menggunakan teori yang sudah ada. Secara praktis peneliti melakukan penelitian secara langsung, baik dalam bentuk studi pustaka maupun lapangan, seolah-olah dengan kepala kosong. Melalui proses penelitian tersebutlah akan lahir teori, berbagai konsep yang dihasilkan oleh peneliti sendiri pada saat memecahkan berbagai masalah. Kemungkinan lain yang timbul, teori akan disimpulkan oleh orang lain bukan peneliti tersebut. Kondisi dilematis juga terjadi dengan mempertimbangkan cara kedua sebab untuk menemukan teori grounded, maka teori-teori sebelumnya sebagai teori formal seolah-olah tidak diperlukan. Teori grounded akan dihasilkan melalui penelitian yang bersangkutan. Menurut Glaser dan Strauss (1967: 1) menyatakan yang terpenting adalah teori grounded karena dapat mengetahui kemampuan dari peneliti. Sedangkan menurut
Vredenbreght (1983 : 2-3) menyatakan teori formal lebih penting karena sudah diuji kevaliditasannya. Terlepas dari perbedaan pendapat tersebut teori formal dan teori grounded perlu untuk dipelajari. Teori mengajarkan kita untuk berpikir kritis, menemukan sekaligus memecahkan masalah. Kemampuan untuk menemukan latar belakang dan masalah, tujuan dan manfaat, dan berbagai komponen penelitian dan dengan sendirinya penyusunan suatu karya ilmiah secara lengkap didasarkan pada pemahaman kita terhadap teori-teori terdahulu. Berdasarkan pandanganpandangan para ahli tersebut dalam penelitian ini teori yang digunakan untuk menganalisis lontar Tutur Aji Saraswati adalah sebagai berikut:

\section{Teori Strukturalisme}

Seperti telah disebutkan diatas, teori-teori formal yang paling banyak dikenal dalam penelitian dan paling banyak digunakan adalah teori strukturalisme dan poststrukturalisme. Menurut Teeuw (1988 : 120-121) akar struktur sudah ada sejakAristoteles dengan pengertian dasar bahwa setiap gejala terdiri atas unsurunsur. Pengertian yang dimaksudkan diperjelas kembali oleh para kritikus abad modern seperti dikemukan oleh Piaget (Hawkes, 1977 : 16) struktur pada gilirannya dianggap sebagai memiliki tiga cirri pokok yaitu kesatuan, transformasi dan regulasi diri. Karya sastra merupakan kesatuan intrinsik di dalamnya unsur-unsur memiliki kemampuan untuk membentuk unsur-unsur baru, tanpa memerlukan bantuan dari luar dirinya. Strukturalisme sangat luas, berkembang diberbagai bidang ilmu dengan berbagai konsep. Ferdinand de Saussure (1857-1913) sebagai peletak dasar lahirnya teori 
strukturalisme dengan membedakan antara unsure langue dan parole, analisis sinkronis dan diakronis, pemahaman secara sintagmatis dan paradigmatik.

Lontar tutur Aji Saraswati adalah lontar yang berisi ajaran tentang kesukseman,ajaran kerohanian tingkat tinggi yang isinya dapat dibedakan menjadi dua yaitu berisi ajaran tentang kesehatan dan ajaran hidup setelah kematian yang dikenal dengan kemoksaan. Dalam menguraikan ajarannya diawali dengan penyusunan dasa aksara ringkasannya menjadi panca Brahma, panca Brahma menjadi Tri Aksara. TriAksara menjadi Rwa Bhineda, Rwa Bhineda menjadi Eka Aksara dan juga diuraikan mengenai kedudukan dalam alam semesta dan badan serta kegunaannya. Lontar ini merupakan kelompok lontar kemoksaan, jika ingin menggunakan naskah tutur ini sebagai sebuah tuntunan maka haruslah teliti, harus membandingkannya terlebih dahulu dengan naskah yang lain. Dan diperlukan tuntunan seorang guru yang mumpuni dibidang itu untuk membukakan jalan karena sedikit saja keliru dalam mempelajari dan mempraktekkannya akan berakibat fatal dan terhindar dari hal-hal yang tidak diinginkan.

\section{Rician Lontar Tutur Aji Saraswati}

Tutur Aji Saraswati yang kami dapatkan merupakan salinan dari tiga penulis yang berbeda yaitu:

1. Tutur Aji Saraswati yang pertamahasil salinan dari Ida Wayan Badra, tahun 1985, yang ditulis di Griya Pekarangan Budakeling, Karangasem, dengan jumlah 39 halaman.

2 TuturAji Saraswati yang kedua hasil salinan dari I Gusti Nengah Putu, tahun 1985, yang ditulis di Tampwangan, Amlapura,
Karangasem, dengan jumlah 29 halaman.

3. TuturAji Saraswati yang ketiga hasil salinan dari Ida Bagus Made Jelantik tahun 1989, yang ditulis di Griya Kecicang Karangasem, jumlah 39 halaman.

Tutur Aji Saraswati mengandung ilmu pengetahuan tertinggi beserta penjelasannya yang dapat dipergunakan (oleh) orang bijaksana, pengawi, mengetahui segala, mengetahui aksara di Bhuwana Alit dan Bhuwana Agung, mengetahui berbagai ilmu yang terdapat di dalam Wariga Usada, Tutur, Agama, seluruh intisari dan penjelasannya. Adapun letak aksara di BhuwanaAgung adalah sebagai berikut:
Ha Na di Timur
Ca Ra di Tenggara
Ka Sa di Selatan
WaLa di Barat Laut
Ma Ga di Barat
Ba Ta di Barat Daya
Nga Pa di Utara
Da Ja di Timur Laut
Ya Nya di Tengah
Pamada di bawah, Carik di atas, diatasnya Sunya.

Lagi tempat aksara di Bhuwana Alit, Ha pada pikiran, Na pada hati, Ca pada pangkal lidah, Ra pada alis, Ka pada pendengaran, $\mathrm{Sa}$ pada putih mata, Wa pada pinggang, La pada bibir, Ma pada muka, Ga pada leher, Ba pada bahu, Ta pada hidung, Pa pada kaki, Da pada dada, Ja pada hati, Pamada pada jantung, carik pada seluruh persendian, cakepan kedua belah adalah Sakula-Sadewa, Rontalnya Arjuna, talinya Bima, aksaranya Dharma Tanaya.

Sakula tangan kanan, Sadewa tangan kiri, Arjuna pada smara, Bima pada nafas, Dharma 
Tanaya pada ucap. Menyatunya Sang Pandawa pada ucap (sabda).

Adapun dalam wariga susunannya secara terperinci menurut penjuru mata angin : purwa adalah timur, gneya adalah tenggara; daksina adalah selatan; neriti adalah barat daya, pascima barat, wayabya barat laut, utara adalah utara, Madhya ke tengah, Ersanya timur laut.

Dalam lontar ini juga disebut di dalam badan ada dua ONG Kara yang berbeda yaitu ONg Kara Ngadeg dan Ong Kara Sumangsang. Ong Kara Ngadeg adalah perwujudan api pembakar seluruh kekotoran. Sedangkan Ong Kara Nungsang adalah perwujudan amerta. Ang pada pusat, AH pada ubun-ubun. Pertemukanlah itu selalu di dalam pikiran, niatkan sebagai air jatuh pada api, menjadi asap, itulah yang menjadiAtma.

Selain itu juga dipaparkan mengenai cara membersihkan atau membakar penyakit dalam tubuh melalui mantra-mantra disertai tata cara pelaksanaan dan pengucapannya. Selanjutnya dijelaskan pula cara membuat penawar (penyakit).

\section{Proses Filologi yang terjadi dalam lontar TuturAji Saraswati}

1. Saut du meme au meme

Saut du meme au meme yaitu maju dari perkataan ke perkataan yang sama. Pada lontar 1 di baris pertama pada kata Sang wruh ring ring sastra. Kata ring ring menyatakan terjadi sautdu meme au meme.

2. Adanya perbedaan yang disengaja

a Dari carapenulisannya.

Baris 1:

- Pada lontar I kata Aji menggunakan huruf "a" biasa, pada kata $\underline{\text { Saraswasti }}$ menggunakan "s" biasa serta kata Inganggo menggunakan "I kara".

- Pada lontar II kata $\underline{A j i}$ menggunakan "a" kara, dan pada kata Saraswasti menggunakan "s" biasa serta kata Inganggo menggunakan "Ikara".

- Pada lontar III kata Aji menggunakan "a" kara, dan kata Saraswasti menggunakan sesaga (œ) biasa serta kata Inganggo menggunakan "ibiasa".

Baris 2:

- Pada lontar I kata wruh menggunakan "ha" dan pada kata sastrane menggunakan huruf "s" biasa serta penulisan kata Bhuana menggunakan "bkembang"

- Pada lontar II kata wruh menggunakan bisah dan pada kata sastrane $\mathrm{s}$ pertama menggunakan "s" biasa sedangkan "s" kedua menggunakan sesaga (œ) serta penulisan kata Buana menggunakan "b biasa" dan " $n$ " menggunakan "n biasa".

- Pada lontar III kata wruh menggunakan bisah dan pada kata sastrane s diawal menggunakan sesaga (œ) serta Buana menggunakan "b dan $n$ biasa".

Baris 3:

- Pada lontar I kata wruh menggunakan bisah dan pada kata manguasuas menggunakan adeg-adeg diakhir kata, kata 
wariga menggunakan "g biasa"

dan pada kata usadha menggunakan "u biasa" dan menggunakan " $\mathrm{dh} / d$ madu"

- Pada lontar II kata manguasuas menggunakan adeg-adeg diakhir kata, kata warigha menggunakan "gh/g gore" dan pada kata usadha menggunakan sesaga dan menggunakan "dh/dmadu"

- Pada lontar III kata manguasuas tidak menggunakan adeg-adeg diakhir kata, kata warigha menggunakan "gh/g gore" dan pada kata $\underline{u}$ sadha menggunakan "u kara" dan menggunakan " $\mathrm{dh} /$ d madu"

b. Adanya penambahan dan pengurangan kata dalam setiap kalimat

- Pada lontarI

"nyandang ingange de Sang wruh ring ring sastra”.

"akar para kabeh muah wruh ring sastra".

"ha na ring purwa, ca ra ring gneyan, ka sa ring kidul, wa la ring neriti, ma ga ring kulwan".

- Pada lontarII

"leng inganggo de Sang wruh ring mang Hyang sastra".

"ga krera kabeh wruh pua sira ring sastra".

"ha na pur cara gne ka sa daksina ning ma ga ku ba ta ngawa u daja jha sanya”.

- Pada lontarIII

"wnang inganggo den Sang wruh ring Sang Hyang nema”. "akrera kabeh wruh ring sastra”. "ha na ring purwa cara ring gneyan ka ra ring kidul wa la ring nariti maga ring kulon".

\section{Nilai- Nilai yang Terkandung Dalam Lontar TuturAji Saraswati}

Nilai-nilai yang terkandung dalam lontar tuturAji Saraswati adalah nilai pendidikan. Hal tersebut dapat dilihat isi lontartuturAji Saraswati tentang aksara Bali yang terdapat dalam Bhuana Agung alam semesta dan Bhuana Alit tubuh manusia yang terdapat pada wariga, usada (ilmu pengobatan), tutur (ilmu kesukseman), ajaran Agama. Aksara atau huruf Bali tersebut digunakan untuk mengetahui letak aksara Bali dalam kehidupan serta oleh para masyarakat yang ingin mendalami ajaranajaran tentang religiusitas aksara tersebut. Berikut adalah kutipan aksara yang terdapat dalam Bhuana Agung (alam semesta) yaitu:

"Sastrane ring bhuana agung ha na ring purwa, ca ra ring gneyan, ka sa ring kidul, wa la ring neriti, ma ga ring kulon, ba ta ring wayabya, ta pa ring utara, da ja ring airsania, nya wa ring madia, pa da ma ring sor, carik ring akasa".

Artinya :

Aksara atau huruf yang ada pada Bhuana Agung (alam semesta) Ha na berada disebelah timur (purwa), ca ra berada disebelah tenggara (genyan), ka sa berada disebelah selatan (kidul), wa la berada disebelah barat daya (naitri), ma ga berada disebelah barat (kulon), ba ta berada disebelah barat laut (wayabya), nga pa berada disebelah utara (utara), da ja berada disebelah timur laut (airsania), nya wa berada ditengah (madia), pa ma da berada dibawa, carik berada diangkasa pada tempat yang sepi. 


\section{PENUTUP}

Tutur Aji Saraswati merupakan kumpulan mantra-mantra yang memiliki kebenaran sejati (tattwa) yang berguna bagi kehidupan masyarakat, khususnya umat Hindu. Tutur Aji Saraswati bermanfaat agar pembaca dapat mengetahui aksara di Bhuwana Alit dan Bhuwana Agung, serta mengetahui berbagai ilmu yang terdapat di dalam Wariga Usada, Tutur,Agama, seluruhintisari dan penjelasannya. Dalam pengucapan mantra maupun pelaksanaan suatu upacara selalu ditekankan untuk menyesuaikan dengan gagelaran silakrama dari Ngku Sangkul Putih, seperti mantra untuk menciptakan tirtha, mantra untuk mempersembahkan peras, mantra menghaturkan Teheran, mantra Panglukatan, mantra untuk menangkap leak dan beberapa mantram penting lainnya. Dalam lontar ini juga dipaparkan bahwa ajaran Siwadrawa adalah ajaran tertinggi, Siwatattalingga Suksma namanya yang merupakan meditasi tertinggi dasar ajaran kemoksan. Tutur Kamoksan yang bernama Sang Hyang Sunya. Tanpa maya, keutamaan tertinggi, sebagai jalan Pitara-nya pulang ke sunya loka; tidak banyak intisari yang utama itu, hanya Sang Hyang Tiganjanasunya di dalam badan yang sejatinya yaitu Siwa, Sadasiwa, Paramasiwa yang stananya pada Ardhacandra, Windu dan Nada. Hati adalah Ardhacandra, empedu adalah windu, jantung adalah Nada. Hati Brahma dewanya, Siwa disana, I Lengengrat Bhuwana namanya. Empedu Wisnu dewanya, Sadasiwadisana, pengasuh yang menjaga I Rangkus Ratna Kusuma namanya. Jantung Iswara dewanya, Paramasiswa disana.

Dapat dijelaskan juga disini bilamana pengaruh mâyâ sudah demikian besarnya terhadap Úiwatma menyebabkan kesadaran aslinya hilang dan sifatnya menjadi “Awidya”. 
Dan apabila kesadarannya terpecah-pecah dan menjiwai semua makhluk hidup termasuk didalamnya adalah manusia, maka Ia disebut Atma dan Jiwatman. Meskipun Atma merupakan bagian dari Sanghyang Widhi (SIWA), namun karena adanya belenggu Awidya yang ditimbulkan oleh pengaruh Maya (Prdhana Tattwa), maka Ia tidak lagi menyadari asalnya. Hal ini menyebabkanAtmaada dalam lingkungan Sorga-Neraka-Samsara secara berulang-ulang. Atma akan dapat bersatu kembali kepada asalnya, apabila semua selaras dengan ajaran Catur Iswarya, Panca Yama Brata, Panca Niyama Brata dan Astasiddhi. Dan apabila dalam segala karmanya bertentangan dengan ajaran-ajaran tersebut tadi, maka Atma akan tetap berada dalam lingkaran Samsara dan Reinkarnasi. Bentuk atau wujud Reinkarnasi Atma sangatbanyak tergantung karma wasananya Atma pada saat penjelmaannya terdahulu. Salah satu bentuk Reinkarnasi itu adalah sebagai "Sthawara Janggama” yang disebutkan sebagai penjelmaan yang paling jelek. Bentuk reinkarnasi seperti itu adalah suatu penderitaan luar biasa yang harusdihadiri

\section{DAFTAR PUSTAKA}

Endraswara, Suwardi. 2008. Metodelogi Penelitian Sastra. Jakarta: FBS Universitas Negeri Yogyakarta.

Gautama, Budha. 2009. Tata Bahasa Kawi.

Denpasar: CV Kayumas Agung

Mardiwarsito. 1990. Kamus Jawa Kuno (Kawi)-Indonesia. Nusa Tenggara Timur: Nusa Indah

Widiawati, Harfiyah. 2010. Teori Sastra.

Yogyakarta: Jayasura 